\title{
Nerve Conduction Study of the Superficial Peroneal Sensory Distal Branches in Koreans
}

\author{
Yeong-A Ko, M.D., Young Jin Ko, M.D., Ph.D., Hye Won Kim, M.D., Ph.D., Seong Hoon Lim, M.D., Ph.D., \\ Byung Woo Yang, M.D., Sung-Hee Jung, M.D., Sun Im, M.D., Ph.D.
}

Department of Rehabilitation Medicine, College of Medicine, The Catholic University of Korea, Bucheon 420-717, Korea

Objective To perform nerve conduction studies of the four branches of the superficial peroneal nerves to determine normal values and anatomic variations in Koreans.

Method Antidromic sensory nerve conduction studies of the four distal branches were performed on 70 healthy subjects (100 feet). We applied electrical stimulation at the midpoint of medial and lateral malleoli for the medial dorsal cutaneous nerve (MDCN), and at the lateral 1/4 point between the medial and lateral malleoli for the 2 branches of the intermediate dorsal cutaneous nerve (IDCN).

Results Reference values (mean $\pm \mathrm{SD})$ of the onset/ peak latency $(\mathrm{ms}) /$ sensory action potential amplitude $(\mu \mathrm{V})$ for the two branches of the MDCN and for the first branch of the IDCN were $2.2 \pm 0.3 / 2.9 \pm 0.3 / 9.2 \pm 3.1,2.2 \pm 0.3$ / $2.8 \pm 0.3 / 9.1 \pm 3.0$ and $2.3 \pm 0.4 / 2.9 \pm 0.3 / 8.5 \pm 2.8$, respectively. For the second IDCN branch, the reference values were $2.3 \pm 0.4 / 3.0 \pm 0.4 / 7.1 \pm 2.6$ but anomalous sural innervation was also found. Three types of IDCN innervations to the fourth interdigital web space were detected. In type I, the fourth interdigital webspace was innervated solely by the IDCN, whereas in type II, it was innervated by both the IDCN and distal sural nerve. In type III, it was solely innervated by the distal sural nerve.

Conclusion The results of this study show the reference values of the distal sensory branches of the superficial peroneal nerve, and provide information on the variant innervations to the fourth interdigital web space.

Key Words Superficial peroneal, Sensory nerve, Reference values, Innervations, Variant

\section{INTRODUCTION}

Nerve conduction studies (NCS) for the distal nerve of the lower limbs are broadly used as a standard diagnostic

Received August 27, 2010; Accepted March 25, 2011

Corresponding author: Sun Im

Department of Rehabilitation Medicine, College of Medicine, The Catholic University of Korea, 2, Sosa-dong, Wonmi-gu, Bucheon 420-717, Korea

Tel: +82-32-340-2170, Fax: +82-32-340-2173, E-mail: lafolia@catholic. ac.kr

(a) This is an open-access article distributed under the terms of the Creative Commons Attribution Non-Commercial License (http://creativecommons.org/ licenses/by-nc/3.0) which permits unrestricted noncommercial use, distribution, and reproduction in any medium, provided the original work is properly cited.

Copyright $\odot 2011$ by Korean Academy of Rehabilitation Medicine tool for screening and making an early diagnosis of polyneuropathy and peripheral neuropathy of the lower limbs. Among them, the diagnostic criteria reported as the most useful is the latency of the sural nerve conduction..$^{1-3}$ In addition, conduction of the lateral dorsal sural nerve, ${ }^{4}$ the medial plantar nerve, and other nerves have been recommended $d^{5,6}$ as useful. However, some researchers have reported that the superficial peroneal sensory nerve and its distal branches are more useful as diagnostic criteria of peripheral neuropathy than the sural nerve alone..$^{7-9}$ Although many different techniques have been suggested for NCS of the superficial peroneal sensory nerve, most are conducted 
at the proximal part of the ankle. ${ }^{7,10,11}$ Therefore, they do not reflect lesions distal to the ankle. Oh et al. ${ }^{12}$ were the first to report on the NCS technique and reference value of the distal branches of the superficial peroneal sensory nerve, and found anatomical variations to be present in only $2.7 \%$ of the study participants. On the other hand, according to research based on cadaveric dissection, ${ }^{13,14}$ anatomical variations in the nerve distribution of the medial dorsal cutaneous nerve (MDCN) and the intermediate dorsal cutaneous nerve (IDCN), are more common than those reported by $\mathrm{Oh}$ et al. ${ }^{12}$ In particular, IDCN is known to have more variations than the MDCN due to its anatomical relationship with the sural nerve. ${ }^{14}$

Despite reports on the various anatomical variations of the IDCN, electromyographic reports relevant to these anatomic variations of the distal branches of the superficial peroneal sensory nerves have not been reported. In addition, data on the reference values of each distal branch based on a healthy Korean cohort have not been reported yet, except for the nerve branch to the hallux from MDCN reported by Ko et al. ${ }^{15}$ in 1998. For these reasons, the objectives of this study are to report on the standardized nerve conduction study reference values of the 4 branches of the distal superficial peroneal sensory nerve in a Korean cohort group, and to determine the presence of any variation present in the distribution of the IDCN.

\section{MATERIALS AND METHODS}

\section{Subjects}

Fifty right feet from 50 healthy volunteers ( 25 men, 25 women) whose age was between 20 and 45 , with no past history of clinical symptoms of neuropathy such as tingling sensation on the lower limbs, sensory decrease, and motor weakness, or with no previous diagnosis of diseases that can cause peripheral neuropathy such as diabetes mellitus, chronic alcohol intake and renal failure, and with no episode of ankle sprain or trauma, were recruited for this study. Data from 2 subjects were excluded from the final NCS analysis, and a total of 48 right feet from 48 participants (24 males, 24 females) were examined. To compare right and left discrepancy, additional NCS was performed from the left feet of 8 participants and from the bilateral feet of 22 participants (10 men, 12 women) whose age was between 20 and 64 . Therefore, the study was conducted on a total of 70 participants (34 males, 36 females), using 100 feet, with bilateral SNAPs obtained from 30 subjects. The protocol of this study was approved by the ethical board committee, and all participants agreed to a formal written consent before the study.

\section{Methods}

Electromyography instrumental condition and test environment: We used Medelec Synergy (Oxford Instrument, Surrey, United Kingdom), with the range of upper and lower frequency filter of sensory nerve conduction study set from $20 \mathrm{~Hz}$ to $2 \mathrm{kHz}$. In addition,
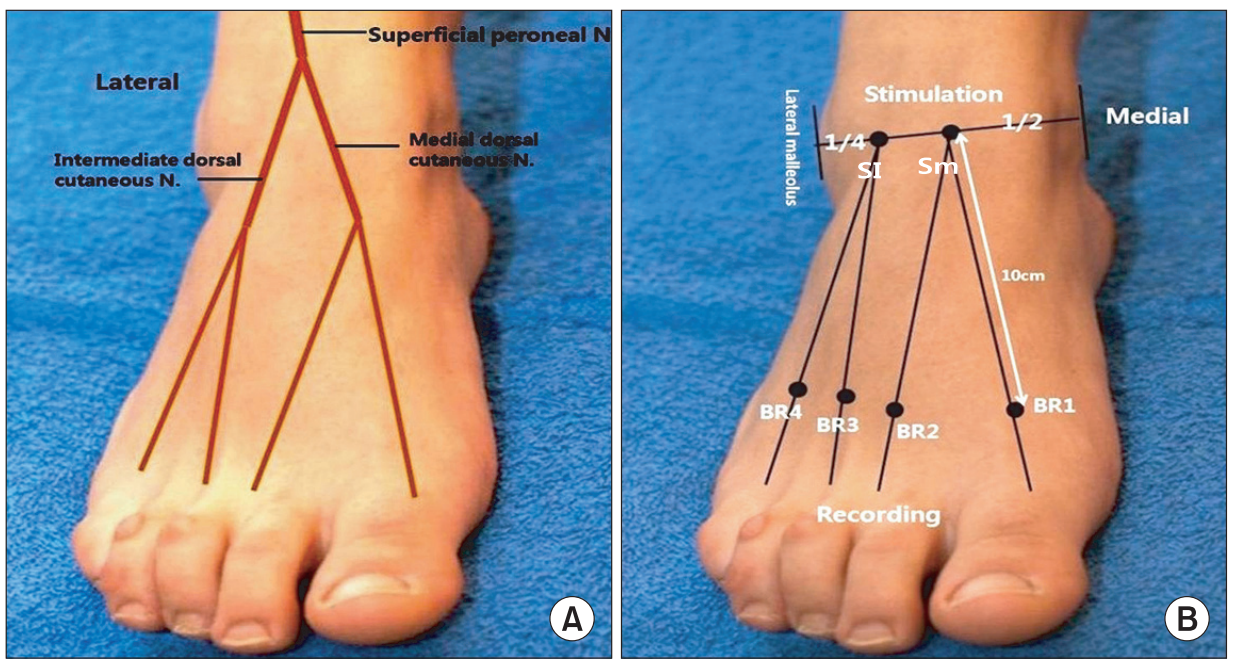

Fig. 1. (A) Anatomical courses of the medial and intermediate dorsal cutaneous nerves. (B) Placement of the recording electrodes and stimulator for recording the sensory action potential from the two branches of the MDCN and IDCN of the superficial peroneal nerve, as suggested by Oh. (Sm: stimulating electrode of MDCN, SI: stimulating electrode of IDCN, BR1: recording electrode of first branch of MDCN, BR2: recording electrode of second branch of MDCN, BR3: recording electrode of first branch of IDCN, $\mathrm{BR} 4$ : recording electrode of second branch of IDCN). 
sweep speed was maintained at $1 \mathrm{~ms} /$ division, with sensitivity at $10 \mu \mathrm{V} /$ division, stimulation duration at $0.05 \mathrm{~ms}$, and intensity at $20-30 \mathrm{~mA}$. Stimulation intensity increased gradually until the maximal sensory response was achieved, and we measured sensory nerve action potentials (SNAPs) by averaging the action potentials evoked from 5-10 responses. Skin temperature of the subjects was maintained above $32^{\circ} \mathrm{C}$. Subjects were in the supine position with their knee extended and ankles on the neutral position. Nerve conduction study was performed by 2 skilled physicians from the department of rehabilitation. The physicians checked all action potentials evoked via orthodromic and antidromic conduction, and recorded them based on antidromic conduction values, which result in a larger amplitude value. Surface electrodes were used for all the recording electrodes.

Electrodiagnostic studies to exclude peripheral polyneuropathy: To exclude the presence of peripheral polyneuropathy, sural and superficial peroneal sensory $\mathrm{NCS}^{16}$ were performed by a standardized method. ${ }^{16,17}$ For sural NCS, an active recording electrode was positioned on the lateral malleolus, between the lateral malleolus and the Achilles tendon, with electrical stimulation performed $14 \mathrm{~cm}$ proximal to the active recording electrode right below the ventral part of gastrocnemius muscle. For the superficial peroneal sensory NCS, the active recording electrode was positioned on the lateral $1 / 3$ area between both malleoli, and stimulation was performed between the anterior to peroneus longus and tibialis anterior muscle.

Sensory NCS on the lateral dorsal sural nerve: To check
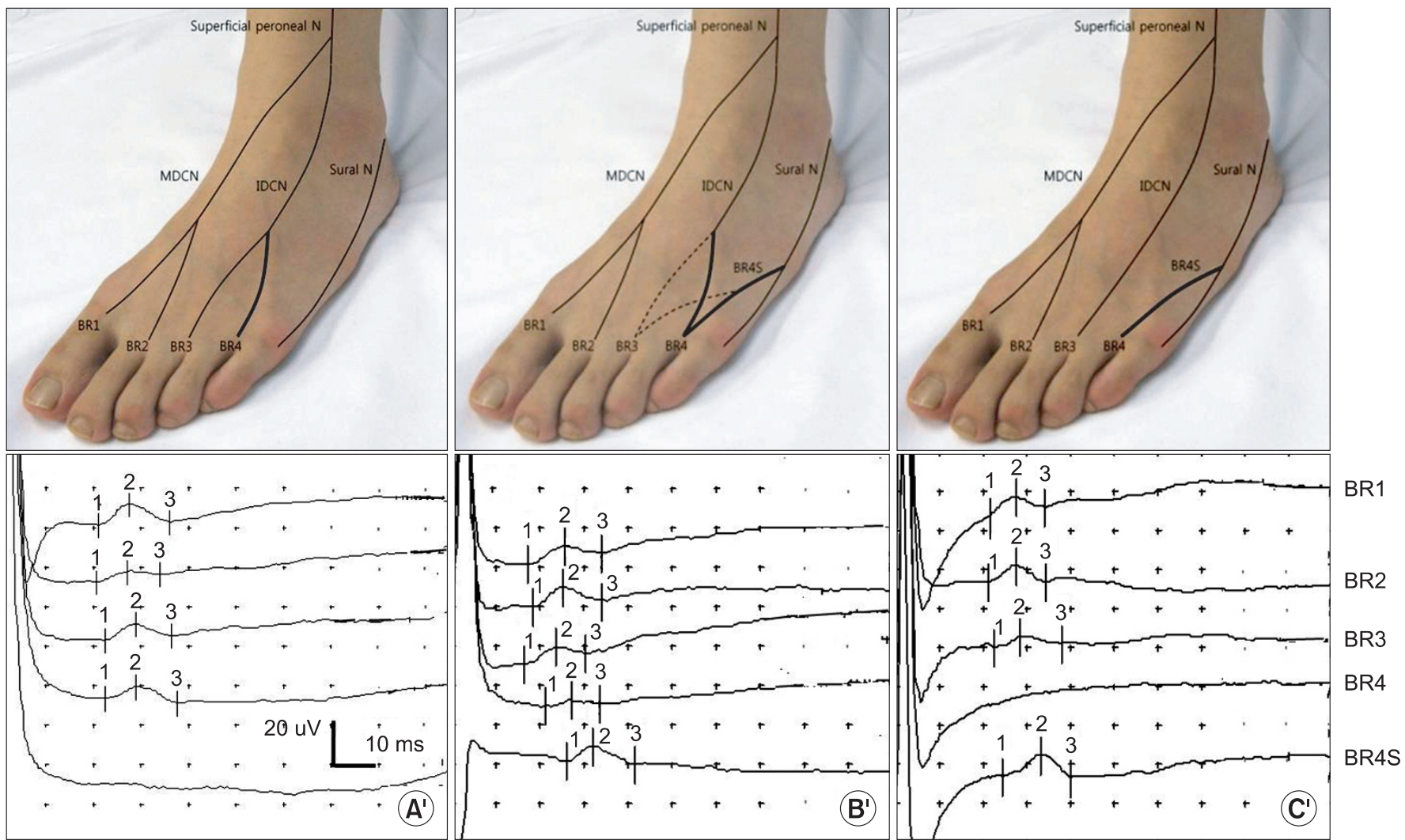

Fig. 2. The three proposed innervation types of the distal branches for the superficial peroneal nerve and their corresponding sensory nerve action potential waveforms recorded with Medelec Select (A): type 1, typical innervation type, (A'): all SNAPs are obtained in all four branches. (B): type 2, dual innervations type from the IDCN and sural nerve, (B'): SNAP amplitudes for BR4 are small and an additional potential (BR4S) is detected with sural nerve stimulation. (C): type 3, sole sural nerve innervation type, (C'): BR4 SNAP is not evoked with IDCN stimulation but a SNAP is recorded with sural nerve stimulation. (N: nerve, BR: branch, BR1, BR2: $1^{\text {st }}$ and $2^{\text {nd }}$ branches of MDCN, BR3, BR4: $1^{\text {st }}$ and $2^{\text {nd }}$ branches of IDCN, BR4S: variation of BR4 with sural innervation, MDCN: Medial dorsal cutaneous nerve, IDCN: Intermediate dorsal cutaneous nerve, SNAP: sensory nerve action potential). 
the integrity of the distal sensory system of the feet, NCS of the lateral dorsal sural nerve (LDSN) was performed according to a previously suggested method. ${ }^{18}$ The active recording electrode was positioned on the dorsolateral surface, at the central part of the $5^{\text {th }}$ metatarsal bone, lateral to the extensor digitorum brevis muscle of the $5^{\text {th }}$ digit. The reference electrode was attached distal to the active recording electrode. Electric stimulation was performed $12 \mathrm{~cm}$ posterior to the lateral malleolus.

Sensory NCS of the branches of distal superficial peroneal sensory nerve: Antidromic conduction was performed using the method suggested by Oh et al. ${ }^{12}$ Two branches to the first and third toes of MDCN and two branches to the fourth and fifth toes of the IDCN were studied with surface stimulation and recording of electrodes (Fig. 1). BR1 and BR2 were defined as the 'two branches to the first and third toes of MDCN' and BR3 and BR4 were defined as the 'two branches to the fourth and fifth toes of the IDCN'. Landmark sites for the electrical stimulation for the MDCN were the midpoint between the medial and lateral malleolus, and for the ICDN at the one quarter distance from the lateral to the medial malleolus. The distance between the stimulating and recording electrodes was set at $10 \mathrm{~cm}$. Recording sites for BR1, BR2, BR3, and BR4 were $10 \mathrm{~cm}$ distal to the stimulating site along a line from the midportion of the hallux or from the interdigital space in other branches. Reference electrodes were attached $3 \mathrm{~cm}$ distal to each active electrode, as shown in Fig. 1.

In cases where SNAP amplitudes were small or not evoked with BR4, the sural nerve was stimulated to confirm for any variation to BR4. When the sural nerve was stimulated, orthodromic and antidromic conduction methods were used to rule out possible volume conduction, and SNAP evoked by antidromic stimulation at the $14 \mathrm{~cm}$ point toward the lateral malleolus was used for analysis. In consideration to previous reports on the variant innervation to the fourth interdigital web space, we performed additional electoral stimulation to the BR4 and defined the SNAP potential obtained with sural nerve stimulation as the variant innervation to BR4 (BR4S) (Fig. 2).

\section{Statistical analysis}

All the results of NCS are presented as mean \pm standard deviation (SD). Reference values of each branch were used for statistical analysis after confirmation of normal distribution. In the presence of any skewness, transformation was performed so that all values followed a normal distribution. To determine NCS normal values and the lower and upper normative limits, we obtained mean $\pm 2 S D$ values of these transformed data as previously published, ${ }^{19-21}$ and then reconverted their endpoints back to the original unit using the opposite mathematical equation.

We classified NCS results according to anatomic variation, depending on whether the sensory of the $4^{\text {th }}$ interdigital webspace was innervated by the superficial peroneal sensory nerve alone, by the sural nerve, or by both nerves. In addition, mean $\pm 2 S D$, lower and upper normative limits of each value were obtained for each anatomic variant type. To identify if there were any significant differences among NCS values of each branch from each subtype, one-way analysis of variance (ANOVA) was performed, and BR4 and BR4S were compared using the paired T-test. Among the 30 participants, who underwent NCS analysis for both sides, analysis was performed (n-24) after exclusion of those who showed a different subtype (n-6) We used the independent T-test to determine any gender difference. The significance level of all the statistical tests was set as $\mathrm{p}<0.05$, and missed values in each analysis were excluded. All the statistical analysis was performed by SPSS (Chicago, IL, USA).

\section{RESULTS}

The mean \pm SD age of the participants were $31.1 \pm 7.7$, with a mean \pm SD height of $169.1 \pm 8.7 \mathrm{~cm}$ (Table 1). Absent SNAPs of the right lower limb were observed in 2 participants and their NCS data were excluded from

Table 1. General Characteristic of Study Participants

\begin{tabular}{lccc}
\hline & Men & Women & Total \\
\hline Number & 34 & 36 & 70 \\
Age (years) & $32 \pm 7.7$ & $30 \pm 7.9$ & $31 \pm 7.7$ \\
Height $(\mathrm{cm}){ }^{*}$ & $175.8 \pm 5.1$ & $162.8 \pm 6.4$ & $169.1 \pm 8.7$ \\
Weight $(\mathrm{kg}){ }^{*}$ & $73.7 \pm 10.0$ & $56.9 \pm 8.6$ & $65 \pm 12$ \\
Body mass index * & $23.8 \pm 3.1$ & $21.5 \pm 3.3$ & $22.6 \pm 3.4$ \\
Foot size $(\mathrm{mm})^{*}$ & $270.2 \pm 11.3$ & $238.6 \pm 19.9$ & $253.5 \pm 22.7$ \\
\hline
\end{tabular}

* $\mathrm{p}<0.05$ by independent $\mathrm{T}$ test, Total feet number: 100 (right 70, left 30) 
the final analysis. SNAPs were evoked in 48 limbs from the remaining 70 participants. SNAP values of the distal superficial peroneal, sural and LDSN nerves showed normal values similar to those previously reported (Table 2). ${ }^{12,15}$

Three types of IDCN innervations to the fourth inter-

Table 2. Summary of Parameters Used in the Sensory Nerve Conduction Studies

\begin{tabular}{lcc}
\hline $\begin{array}{c}\text { Sensory nerve } \\
\text { N=48 }\end{array}$ & $\begin{array}{c}\text { Amplitude } \\
\text { SNAP }(\mu \mathrm{V})\end{array}$ & $\begin{array}{c}\text { Latency } \\
\text { Onset/Peak }(\mathrm{ms})\end{array}$ \\
\hline $\begin{array}{l}\text { Lateral dorsal } \\
\text { sural }\end{array}$ & $8.8 \pm 1.8$ & $2.3 \pm 0.3 / 3.0 \pm 0.3$ \\
Sural & $17.6 \pm 5.2$ & $2.4 \pm 0.3 / 3.2 \pm 0.4$ \\
$\begin{array}{l}\text { Superficial } \\
\text { peroneal }\end{array}$ & $14.4 \pm 3.9$ & $2.4 \pm 0.3 / 3.1 \pm 0.3$ \\
\hline
\end{tabular}

Mean \pm S.D.

SD: Standard deviation, SNAP: Sensory nerve action potential
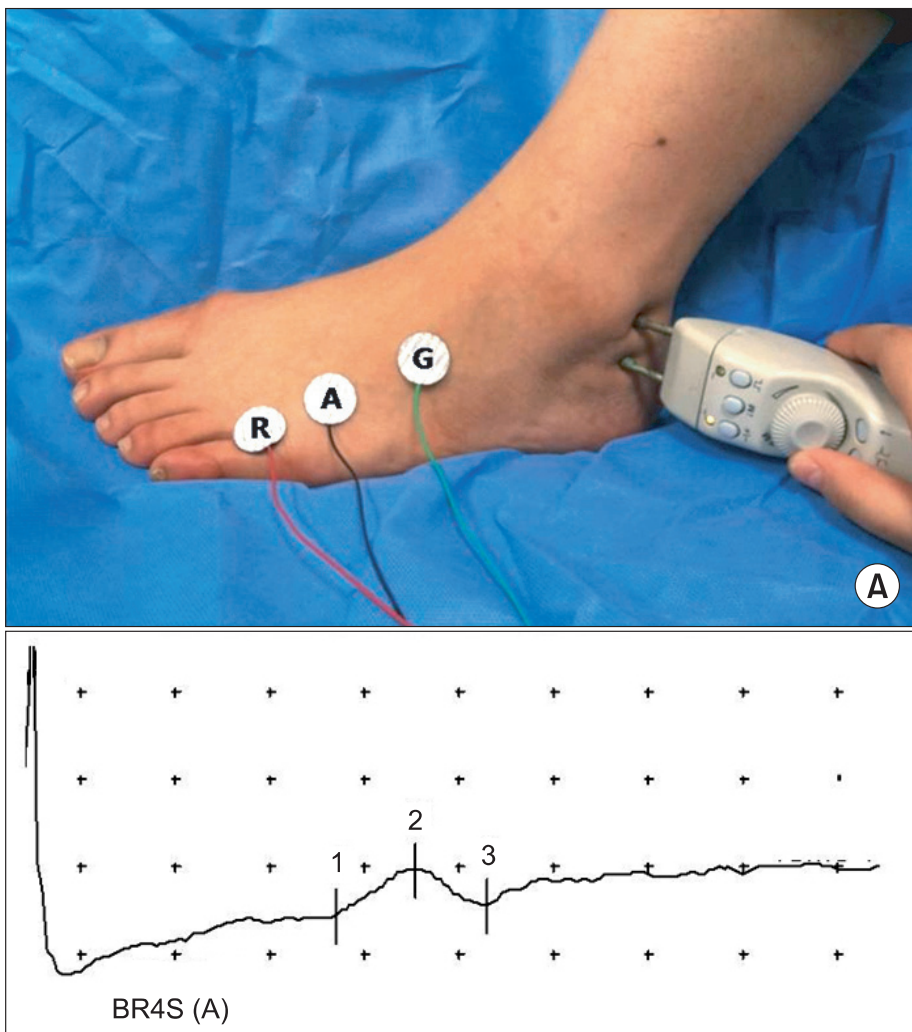

(A)

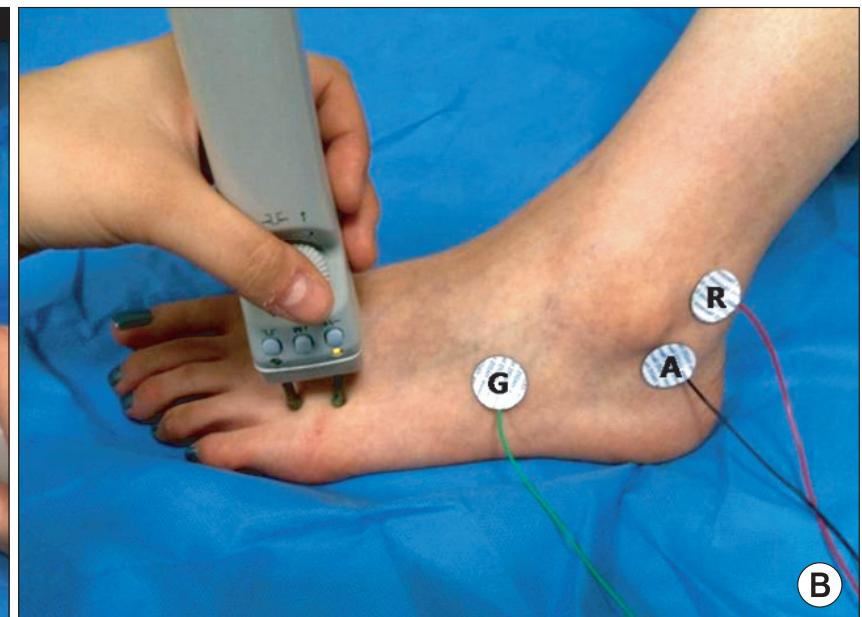

digital web space were detected (Table 3). In type I, the fourth interdigital webspace was innervated solely by the IDCN. In type II, it was innervated by both the IDCN and distal sural nerve. In type III, it was solely innervated by the distal sural nerve (Fig. 2). In BR4S, orthodromic and antdromic responses showed similar waveforms and the presence of volume conduction or an artifact were ruled

Table 3. Three Innervations Types of IDCN to the $4^{\text {th }}$ Webspace

\begin{tabular}{llc}
\hline \multicolumn{1}{c}{ Type } & \multicolumn{1}{c}{ Innervation } & $\begin{array}{c}\text { Numbers (\%) } \\
\mathbf{N = 1 0 0}\end{array}$ \\
\hline Type I (Standard) & $\begin{array}{l}\text { Distal superficial } \\
\text { peroneal nerve }\end{array}$ & $36(36)$ \\
Type II (Dual) & $\begin{array}{l}\text { Distal superficial } \\
\text { nerve+sural nerve }\end{array}$ & $31(31)$ \\
$\begin{array}{l}\text { Type III } \\
\text { (Sural only) }\end{array}$ & Sural nerve & $35(35)$ \\
\hline
\end{tabular}

IDCN: Intermediate dorsal cutaneous nerve

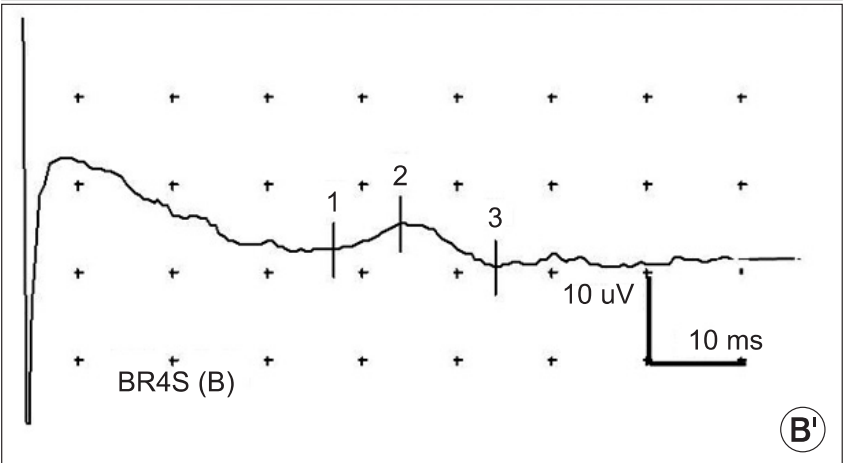

Fig. 3. BR4S antidromic and orthodromic SNAP waveforms recorded with Medelec Select (A): Stimulation with antidromic method, (A'): BR4S SNAP evoked with the antidromic method. (B): Stimulation with the orthodromic method, (B'): BR4s SNAP evoked with the orthodromic method. (BR4: $2^{\text {nd }}$ branch of IDCN, BR4S: variation of BR4 with sural innervation, SNAP: sensory nerve action potential). 
Table 4. Normal Reference Values of Distal Branches of the Superficial Peroneal Nerve of Each Innervation Subtype (Total Number 100, Type $1: 36$. Type $2: 31$, Type $3: 35$ )

\begin{tabular}{|c|c|c|c|c|c|c|}
\hline & & \multirow{2}{*}{$\begin{array}{c}\text { BR1 (MDCN) } \\
\text { Mean } \pm \text { SD } \\
\left(\mathrm{L} / \mathrm{U} \text { range }{ }^{*}\right)\end{array}$} & \multirow{2}{*}{$\begin{array}{c}\text { BR2 }(\mathrm{MDCN}) \\
\text { Mean } \pm \text { SD } \\
(\mathrm{L} / \mathrm{U} \text { range })\end{array}$} & \multirow{2}{*}{$\begin{array}{c}\text { BR3 }(\text { IDCN }) \\
\text { Mean } \pm S D \\
\left(\mathrm{~L} / \text { U range } \text { ran }^{*}\right.\end{array}$} & \multirow{2}{*}{$\begin{array}{c}\text { BR4 }(\text { IDCN }) \\
\text { Mean } \pm \text { SD } \\
(\mathrm{L} / \text { U range* })\end{array}$} & \multirow{2}{*}{$\begin{array}{c}\text { BR4S (Sural) } \\
\text { Mean } \pm \text { SD } \\
\left(\mathrm{L} / \mathrm{U} \text { range }{ }^{*}\right)\end{array}$} \\
\hline & & & & & & \\
\hline \multirow[t]{3}{*}{ Type 1} & Onset latency (ms) & $\begin{array}{c}2.2 \pm 0.3 \\
(1.6-2.5)\end{array}$ & $\begin{array}{c}2.1 \pm 0.3 \\
(1.6-2.4)\end{array}$ & $\begin{array}{c}2.3 \pm 0.4 \\
(1.7-2.6)\end{array}$ & $\begin{array}{c}2.2 \pm 0.4 \\
(1.6-2.6)\end{array}$ & Not evoked \\
\hline & Peak latency (ms) & $\begin{array}{c}2.9 \pm 0.4 \\
(2.2-3.3)\end{array}$ & $\begin{array}{c}2.8 \pm 0.3 \\
(2.2-3.1)\end{array}$ & $\begin{array}{c}3.0 \pm 0.2 \\
(2.5-3.2)\end{array}$ & $\begin{array}{c}3.0 \pm 0.3 \\
(2.4-3.4)\end{array}$ & Not evoked \\
\hline & SNAP amplitude $(\mu \mathrm{V})$ & $\begin{array}{c}9.0 \pm 3.4 \\
(3.6-12.7)\end{array}$ & $\begin{array}{c}9.0 \pm 3.3 \\
(4.1-12.2)\end{array}$ & $\begin{array}{c}9.1 \pm 2.9 \\
(4.4-12.1)\end{array}$ & $\begin{array}{c}8.0 \pm 2.3 \\
(4.0-10.6)^{\dagger}\end{array}$ & Not evoked \\
\hline \multirow[t]{3}{*}{ Type 2} & Onset latency (ms) & $\begin{array}{c}2.2 \pm 0.2 \\
(1.7-2.4)\end{array}$ & $\begin{array}{c}2.1 \pm 0.3 \\
(1.6-2.4)\end{array}$ & $\begin{array}{c}2.2 \pm 0.2 \\
(1.8-2.5)\end{array}$ & $\begin{array}{c}2.3 \pm 0.4 \\
(1.6-2.7)\end{array}$ & $\begin{array}{c}3.4 \pm 0.8 \\
(2.2-4.1)\end{array}$ \\
\hline & Peak latency (ms) & $\begin{array}{c}2.8 \pm 0.3 \\
(2.3-3.1)\end{array}$ & $\begin{array}{c}2.8 \pm 0.3 \\
(2.2-3.1)\end{array}$ & $\begin{array}{c}2.9 \pm 0.3 \\
(2.3-3.2)\end{array}$ & $\begin{array}{c}2.9 \pm 0.4 \\
(2.2-3.3)\end{array}$ & $\begin{array}{c}4.2 \pm 0.8 \\
(2.8-4.9)\end{array}$ \\
\hline & SNAP amplitude $(\mu \mathrm{V})$ & $\begin{array}{c}9.0 \pm 3.0 \\
(4.1-12.2)\end{array}$ & $\begin{array}{c}9.1 \pm 3.4 \\
(4.0-12.5)\end{array}$ & $\begin{array}{c}8.5 \pm 3.0 \\
(4.0-11.3)\end{array}$ & $\begin{array}{c}5.9 \pm 2.4 \\
(2.3-8.3)^{\dagger}\end{array}$ & $\begin{array}{c}6.3 \pm 2.9 \\
(2.2-9.1)\end{array}$ \\
\hline \multirow[t]{3}{*}{ Type 3} & Onset latency (ms) & $\begin{array}{c}2.3 \pm 0.2 \\
(1.9-2.6)\end{array}$ & $\begin{array}{c}2.2 \pm 0.3 \\
(1.6-2.5)\end{array}$ & $\begin{array}{c}2.3 \pm 0.4 \\
(1.6-2.7)\end{array}$ & Not evoked & $\begin{array}{c}3.3 \pm 0.6 \\
(2.3-3.9)\end{array}$ \\
\hline & Peak latency (ms) & $\begin{array}{c}3.0 \pm 0.3 \\
(2.5-3.3)\end{array}$ & $\begin{array}{c}2.9 \pm 0.4 \\
(2.2-3.3)\end{array}$ & $\begin{array}{c}2.9 \pm 0.3 \\
(2.4-3.2)\end{array}$ & Not evoked & $\begin{array}{c}4.1 \pm 0.7 \\
(3.0-4.7)\end{array}$ \\
\hline & SNAP amplitude $(\mu \mathrm{V})$ & $\begin{array}{c}9.5 \pm 2.9 \\
(4.9-12.4) \\
\end{array}$ & $\begin{array}{c}9.0 \pm 2.4 \\
(4.9-11.5) \\
\end{array}$ & $\begin{array}{c}7.4 \pm 2.1 \\
(4.0-9.4) \\
\end{array}$ & Not evoked & $\begin{array}{c}7.0 \pm 2.5 \\
(3.0-9.7) \\
\end{array}$ \\
\hline
\end{tabular}

Values are Mean \pm SD

SNAPs: Sensory nerve action potentials, MDCN: Medial dorsal cutaneous nerve, IDCN: Intermediate dorsal cutaneous nerve, SD: Standard deviation, Type 1: Standard type, Type 2: Dual type, type 3: Sural only type, BR1, BR2: $1^{\text {st }}$ and $2^{\text {nd }}$ branches of MDCN, BR3, BR4: $1^{\text {st }}$ and $2^{\text {nd }}$ branches of IDCN, BR4S: Variation of BR4 with sural innervation

*Data were transformed so that they followed a normal distribution. We took the mean \pm 2 SDs of these tansformed data and converted these end points back to their original units using the opposite mathematical function, which were then used as the lower and upper normative range values. ${ }^{\dagger} \mathrm{p}<0.05$ by paired T-test

out (Fig. 3).

The references values of BR1, BR2, BR3, BR4 and BR4S for each subtype are presented (Table 4). ANOVA analysis showed no significant difference in BR1, BR2, and BR3 among all the subtypes. In the paired T-test, a significant difference only in BR4 SNAP amplitude between type 1 and 2 was detected $(\mathrm{p}<0.05)$.

Among the 30 additional participants that were recruited for side to side differences, we detected different subtypes for each side (right-left) in 6 participants (20\%); type 1-type 2 (n-2), type 2-type 3 (n-3), and type 1-type 3 (n-1). No statistical difference of right and left sides was observed in the 24 subjects. No statistical difference was observed in other values. Significant differences were detected between men and women in height, body weight, foot size, and BMI (body mass index). In NCS parameters significant differences of NCS parameter in the onset and peak latencies of BR1 and BR3 were observed. The mean, minimum, and maximum reference value of NCS parameter for all the distal branches from each subtype is summarized (Table 4).

\section{DISCUSSION}

The results of this study showed the reference mean values of the distal sensory branches of the superficial peroneal sensory nerve obtained from a healthy Korean cohort. NCS values obtained through the technique as suggested by Oh et al., ${ }^{12}$ showed that the reference values for the distal branches of the MDCN (BR1, BR2) showed similar reference values as previously reported. ${ }^{12,15}$ In addition, the authors identified 3 variant innervations types of the IDCN to the $4^{\text {th }}$ and $5^{\text {th }}$ digits (BR3, BR4).

Except for the lateral side of the $5^{\text {th }}$ digit and the inter- 
space of the $1^{\text {st }}$ and the $2^{\text {nd }}$ digit, which are innervated by the distal sural nerve and deep peroneal nerve respectively, the dorsum of the foot is mainly innervated by the distal branches of superficial peroneal sensory nerve. However, in the absence of the lateral branches, the lateral dorsum can be innervated by variant innervations from the sural nerve. ${ }^{22}$ The reference values of the distal branches of the superficial peroneal nerve in a Korean cohort have been previously reported by Ko et al., ${ }^{15}$ who reported reference values of the MDCN to the hallux. However, reference values of the other distal branches or the presence of anatomic variation have not been not reported. The results of the present study showed reference values for all the branches of the distal superficial peroneal nerve. In addition, in cases where SNAP potential was not evoked or absent, we confirmed in $66 \%$ of subjects the presence of variant innervations to the $4^{\text {th }}$ interdigital space from the sural nerve.

The superficial peroneal sensory nerve penetrates the fascia at the $1 / 3$ point below the knee, and divides into two branches, the MDCN and IDCN. MDCN passes in front of the ankle joint, and divides into two ventral distal branches, which innervate the medial side of the $1^{\text {st }}$ digit, the $2^{\text {nd }}$ interdigital webspace, and the medial side of the foot and ankle joint. The MDCN has communicating branches to the deep peroneal and saphenous nerves. The IDCN, which is smaller in size, passes along the lateral side of the foot, and divides into ventral distal branches, which innervate the $3^{\text {rd }}$ and the $4^{\text {th }}$ interdigital webspace and the dorsum of the foot and the lateral side of the ankle joint. IDCN also has communicating branches to the sural nerve. ${ }^{22}$

According to cadaveric dissection studies, there are many anatomical variations in the MDCN and IDCN. There are reports on the superficial peroneal sensory nerve branch terminating at the extensor digitorum brevis in $0.8 \%$, without giving off MDCN and IDCN branches ${ }^{13}$ or on the absence of IDCN, or IDCN not innervating the digits in $35 \% .{ }^{14}$ These anatomic variants are reported to be more common in IDCN than MDCN. ${ }^{14}$ According to Kosinski ${ }^{13}$ and Solomon et al., ${ }^{14}$ the incidence of sural nerve anastomosis with the IDCN to the $4^{\text {th }}$ interdigital webspace can be from $1.7-8.8 \%$. In addition, IDCN innervating the 4 th interdigital webspace as the distal branch from LDSN, instead of the superficial peroneal nerve can be present in $34.9-67.7 \%$ of subjects.
In this study, we identified three types of IDCN innervations to the fourth interdigital web space. In type I, the fourth interdigital webspace was innervated solely by the IDCN, whereas in type II, it was innervated by both the IDCN and distal sural nerve. In type III, it was solely innervated by the distal sural nerve without contribution by the IDCN. Variant innervation was present in $66 \%$ of our cases. Although this number is similar to those reported from the cadaveric study ${ }^{13,14}$ our results were different from those reported by Oh et al., ${ }^{12}$ who identified only one case that showed sural nerve variant innervation with the IDCN, and reported variation to be present in only $2.7 \%$. There may be various reasons for this discrepancy, and racial difference between the two studies could be a strong factor.

In side-to-side analysis, although different subtypes of innervations were present in $20 \%$ of our subjects, no difference between right and left NCS values were observed within each subtype, which was in accordance with those suggested by $\mathrm{Oh}$ et al., ${ }^{12}$ This subtype difference of $20 \%$ was lower than the $32 \%$ reported by MartinGruber anastomosis, between the median and the ulnar nerve. $^{23}$

Gender differences in onset and peak latency of BR1 and BR3 were observed in this study. Reports have shown that women manifest larger SNAP amplitude and shorter latency in the upper limb NCS ${ }^{24,25}$ due to smaller digital circumference. ${ }^{24,26}$ In contrast, another report showed no gender difference in the sural nerve. ${ }^{27}$ Other factors such as height and lower extremity length were reported to be major determinants in NCS values, since these factors were related to axonal length. ${ }^{26,28}$ In this study, significant gender differences in height and foot were observed, and we think that the differences observed in BR1 and BR3 latencies were more attributable to these anthropometric values than to gender difference.

MDCN and IDCN NCS can be useful in many clinical circumstances. Peripheral polyneuropathy is known to begin first in the distal part of the lower limbs, ${ }^{29}$ and sensory NCS of the distal sensory branches of the superficial peroneal sensory nerve, along with the sural nerve, was reported to increase the diagnostic sensitivity of peripheral neuropathy. ${ }^{30}$ Also, Kushnir et al. ${ }^{9}$ showed that the SNAP amplitude of MDCN, along with H-reflex and conduction velocity from a tibial motor conduction study were useful in the diagnosis of mild peripheral 
neuropathy, when the sural SNAP showed normal range values. Therefore, assessment of the distal branches of the superficial peroneal sensory nerve could increase the accuracy and sensitivity of diagnosing peripheral polyneuropathy. ${ }^{15}$ In addition, entrapment ${ }^{31}$ could be caused by epidermoid cyst ganglion, ${ }^{32}$ tight shoestring, burn scar, neuropathies induced by trauma, including ankle sprain, ${ }^{33}$ and needle injuries. ${ }^{34}$ In summary, standardized NCS values of the distal branches of the superficial peroneal sensory nerve presented in this study may be useful in the diagnosis of peripheral polyneuropathy and injuries related to the distal part of the ankle joint. The high rate of anatomical variation in IDCN should be considered when making these diagnoses.

The results of this study show a standardized NCS method and reference values of IDCN along with a high rate of anatomic variation of the lateral dorsum of the foot. Therefore, based on these results, if SNAPs were not evoked or their amplitude was discordant with those of other branches especially for the BR4, then before making a final diagnosis of neuropathy, the presence of anatomic variation should be considered and additional NCS with stimulation of the sural nerve should be performed. Taking these anatomic variants and subtypes into consideration as suggested would help to increase the diagnostic accuracy of the NCS findings from these distal sensory nerves.

Some limiting factors of this study need to be considered. First, although we identified a variant of the branch nerve to the $4^{\text {th }}$ interdigital webspace, which is the most common anatomical variation of the lateral dorsal foot, these results may not completely match with the actual anatomical variation since it has been reported that the sural nerve can co-innervate the $3^{\text {rd }}$ interdigital webspace. Second, although Oh et al. ${ }^{12}$, obtained their reference values from both antidromic and orthodromic conduction studies, we reported only the antidromic SNAP values and confirmed the evoked potentials with both techniques. We chose to present the antidromic values because these are larger in size and because most NCS of other lower limb nerves are commonly obtained with the antidromic stimulation. Further studies on the reference values from orthodromic stimulation are warranted for more accurate reference values. Finally, in order to accurately record the exact prevalence of these various anatomical variations in normal Korean adults, further studies that include a larger sample of participants with a broader age range, along with anatomical confirmation are required.

\section{CONCLUSION}

This study presented reference values and innervation subtypes of the distal branches of the superficial peroneal sensory nerve. BR4, which is a branch of the IDCN, showed different variant subtypes related to the sural nerve, and the rate was higher than the rates reported from the other report. ${ }^{12}$ Clinicians should take into account the high rate of anatomic variation of the IDCN when performing NCS of these distal sensory branches.

\section{REFERENCES}

1. Burke D, Skuse NF, Lethlean AK. Sensory conduction of the sural nerve in polyneuropathy. J Neurol Neurosurg Psychiatry 1974; 37: 647-652

2. Braddom RL, Hollis JB, Castell DO. Diabetic peripheral neuropathy: a correlation of nerve conduction studies and clinical findings. Arch Phys Med Rehabil 1977; 58: 308-313

3. Celiker R, Basgze O, Bayraktar M. Early detection of neurological involvement in diabetes mellitus. Electromyogr Clin Neurophysiol 1996; 36: 29-35

4. Ryu GH, Nam KY, Jun JY, Sim YJ, Choi JH, Kwon BS, Park JW, Lim HS. New method and usefullness of study on sensory nerve conduction of lateral sural cutaneous Nerve. J Korean Acad Rehab Med 2008; 32: 300-304

5. Uluc K, Isak B, Borucu D, Temucin CM, Cetinkaya Y, Koytak PK, Tanridag T, Us O. Medial plantar and dorsal sural nerve conduction studies increase the sensitivity in the detection of neuropathy in diabetic patients. Clin Neurophysiol 2008; 119: 880-885

6. Andersen H, Stlberg E, Falck B. F-wave latency, the most sensitive nerve conduction parameter in patients with diabetes mellitus. Muscle Nerve 1997; 20: 1296-1302

7. Jabre JF. The superficial peroneal sensory nerve revisited. Arch Neurol 1981; 38: 666-667

8. Lo YL, Xu LQ, Leoh TH, Dan YF, Tan YE, Nurjannah S, Ratnagopal P. Superficial peroneal sensory and sural nerve conduction studies in peripheral neuropathy. J 
Clin Neurosci 2006; 13: 547-549

9. Kushnir M, Klein C, Kimiagar Y, Pollak L, Rabey JM. Medial dorsal superficial peroneal nerve studies in patients with polyneuropathy and normal sural responses. Muscle Nerve 2005; 31: 386-389

10. Izzo KL, Sridhara CR, Rosenholtz H, Lemont H. Sensory conduction studies of the branches of the superficial peroneal nerve. Arch Phys Med Rehab 1981; 62: 24-27

11. Levin KH, Stevens JC, Daube JR. Superficial peroneal nerve conduction studies for electromyographic diagnosis. Muscle Nerve 1986; 9: 322-326

12. Oh SJ, Demirci M, Dajani B, Melo AC, Claussen GC. Distal sensory nerve conduction of the superficial peroneal nerve: new method and its clinical application. Muscle Nerve 2001; 24: 689-694

13. Kosinski C. The course, mutual relations and distribution of the cutaneous nerves of the metazonal region of leg and foot. J Anat 1926; 60: 274-297

14. Solomon LB, Ferris L, Tedman R, Henneberg M. Surgical anatomy of the sural and superficial fibular nerves with an emphasis on the approach to the lateral malleolus. J Anat 2001; 199: 717-723

15. Ko YJ, Kim HY, Park NK, Kim JK, Jang JY, Kang SY. Conduction study of dorsomedial cutaneous nerve to the great toe. J Korean Acad Rehab Med 1998; 22: 1284-1287

16. Liveson JA, Ma DM. Laboratory reference for clinical neurophysiology, 1st ed, New York, Oxford, 1992, 219226

17. DiBenedetto M. Sensory nerve conduction in lower extremities. Arch Phys Med Rehab 1970; 51: 253-258

18. Lee HJ, Bach HJ, DeLisa JA. Lateral dorsal cutaneous branch of the sural nerve. Standardization in nerve conduction study. Arch Phys Med Rehab 1992; 71: 318-320

19. Dorfman LJ, Robinson LR. AAEM minimonograph \# 47: normative data in electrodiagnostic medicine. Muscle Nerve 1997; 20: 4-14

20. Campbell WW, Robinson LR. Deriving reference values in electrodiagnostic medicine. Muscle Nerve 1993; 16: 424-428

21. Resman-Gaspersc A, Podnar S. Phrenic nerve conduction studies: technical aspects and normative data. Muscle Nerve 2008; 37: 36-41
22. Drake RL, Vogl W, Mitchell AW. Gray's anatomy for students, 39th ed, Philadelphia, Chrchill Livingstone, 2005, 582-584

23. Kimura J, Murphy MJ, Varda DJ. Electrophysiological study of anomalous innervations of intrinsic hand muscles. Arch Neurol 1976; 33: 842-844

24. Bolton CF, Carter KM. Human sensory nerve compound action potential amplitude: variation with sex and finger circumference. J Neurol Neurosurg Psychiatry 1980; 43: 925-928

25. Falco FJ, Hennessey WJ, Braddom RL, Goldberg G. Standardized nerve conduction studies in the upper limb of the healthy elderly. Am J Phys Med Rehab 1992; 71: 263-271

26. Stetson DS, Albers JW, Silverstein BA, Wolfe RA. Effects of age, sex, and anthropometric factors on nerve conduction measures. Muscle Nerve 1992; 15: 1095-1104

27. Trojaborg WT, Moon A, Andersen BB, Trojaborg NS. Sural nerve conduction parameters in normal subjects related to age, gender, temperature, and height: a reappraisal. Muscle Nerve 1992; 15: 666-671

28. Zwarts MJ, Guechev A. The relation between conduction velocity and axonal length. Muscle Nerve 1995; 18: $1244-1249$

29. Killian JM, Foreman PJ. Clinical utility of dorsal sural nerve conduction studies. Muscle Nerve 2001; 24: 817-820

30. Izzo KL, Sobel E, Demopoulos JT. Diabetic neuropathy: electrophysiologic abnormalities of distal lower extremity sensory nerves. Arch Phys Med Rehabil 1986; 67: 7-11

31. Sridhara CR, Izzo KL. Terminal sensory branches of the superficial peroneal nerve: an entrapment syndrome. Arch Phys Med Rehabil 1985; 66: 789-791

32. Nelson GA, Puhl RW, Altman MI. Superficial dysesthesias secondary to epidermoid cyst of the foot. J Foot Surg 1985; 24: 269-271

33. Acus RW 3rd, Flanagan JP. Perineural fibrosis of superficial peroneal nerve complicating ankle sprain: a case report. Foot Ankle 1991; 11: 233-235

34. Preston D, Logigian E. Iatrogenic needle-induced peroneal neuropathy in the foot. Ann Intern Med 1988; 109: 921-922 